\title{
Dubbing attitudes through tonal patterns: when tones speak louder than words
}

\author{
Sofía Sánchez-Mompeán \\ Universidad de Murcia, Spain \\ sofia.sanchez@um.es
}

\begin{abstract}
This article explores the conveyance of attitudinal content through intonation in dubbed dialogue and presents the findings from an empirical corpus-based analysis. Research-wise, intonation is hitherto an understudied topic in Audiovisual Translation and has generally taken a back seat in dubbing literature. However, its communicative value and attitudinal function in oral discourse cannot be overlooked when interpreting and producing dubbed speech. The possibility of associating a particular tonal pattern with specific attitudes has enabled the comparison between a number of English original and Spanish dubbed intonation phrases via a speech analysis software. The results obtained provide empirical data on the dubbing of the attitudinal content under analysis and account for the main trends that could negatively affect both the quality of the final outcome and the way the dubbed text is received by the target audience.
\end{abstract}

Keywords: dubbing, intonation, tonal pattern, attitude, attitudinal content.

\section{Resumen}

El presente trabajo explora el contenido actitudinal que se transmite entonativamente en el diálogo doblado y presenta los resultados de un estudio empírico basado en un corpus. La entonación es a día de hoy un campo de estudio minoritario en Traducción Audiovisual y suele ocupar una posición secundaria en la literatura sobre doblaje. Sin embargo, su valor comunicativo y su función actitudinal en el discurso oral ponen de relieve su importancia a la hora de interpretar y emitir el diálogo doblado. La posibilidad de asociar un patrón tonal determinado con una serie de actitudes ha permitido la comparación entre varias frases entonativas en inglés y en 
español mediante un programa de análisis de voz. Los resultados obtenidos muestran datos empíricos sobre el doblaje del contenido actitudinal analizado y destacan los factores principales que podrían afectar a la calidad del producto final y a la forma en la que la audiencia meta recibe el texto doblado.

Palabras clave: doblaje, entonación, tono, actitud, contenido actitudinal.

\section{Introduction}

All languages are melodic in nature as a result of their prosodic variation. As put by Nilsenová \& Swerts (2012: 78), "there are no languages in which utterances are produced at a constant tempo, in a straight monotone and with no variation in loudness or voice quality". One of the key ingredients for the production of speech melody is intonation, defined by Crystal (1985: 162) as "the distinctive use of patterns of pitch, or melody". This suprasegmental trait, however, cannot simply be described in terms of melodic patterns. Intonation is part and parcel of oral communication and provides a sound basis for coherent conversation, adding meaning to the words uttered by the speakers. As such, it can be considered a powerful source of information that unveils the addresser's inner feelings and implies the linguistic interpretation of pitch contours on the part of the listener (Cantero, 2002).

Despite its importance in oral discourse, intonation has barely been explored within the remit of Audiovisual Translation (AVT) and, more specifically, within the context of dubbing. One of the reasons behind this lack of popularity amongst AVT scholars might be the difficulty to disentangle the intonational system of a language. In fact, as put forward by Hirst \& Di Cristo (1998: 1), "intonation is paradoxically at the same time one of the most universal and one of the most language-specific features of human language". When the attitudinal function of intonation comes into play, such remark becomes even more obvious insofar as different pitch contours can convey different attitudinal meanings and different languages can convey the same attitudes by resorting to different pitch contours (O'Connor \& Arnold, 1973).

This paper gives intonation the attention it merits by bringing its significant role in dubbing to the fore. Focusing on the interplay between the interpretation and production of intonation in original and dubbed dialogues, the present research deals with the (un)successful conveyance of attitudes through tonal patterns in the Spanish dubbed version of one of the most popular American sitcoms on TV: How I met your mother (CBS, 2005-2014). To the best of the researcher's knowledge, this approach has not hitherto been subject of any empirical study in the area of AVT and Linguistics. 
The article starts with a theoretical overview of intonation from a purely functional perspective. The focus is then placed on the attitudinal function of intonation to show how attitudes and tones can converge in speech in search of a successful outcome in dubbing. The next section is devoted to the methods and the bilingual corpus used in the study. An empirical corpus-based analysis will enable the quantitative and qualitative comparison between the source and target utterances under examination in terms of intonation and attitudinal content. This is followed by the discussion of the results obtained in the comparative analysis as well as by the most recurring trends observed in the conveyance of attitudes in the dubbed text. The conclusion emphasizes the relevant role of tonal patterns, which are not simply valuable but fundamental to interpret and reproduce the full richness of the source dialogue.

\section{The functions of intonation}

The functions that intonation can perform in a language are manifold. Wells (2006) argues that this suprasegmental trait can serve a total of six functions in speech, namely attitudinal, grammatical, accentual (or focusing), discourse (or cohesive), psychological and indexical. The first function - of special interest for the purpose of this articleis related to the attitude intended by the speaker with the use of a particular tone. According to Monroy (2005: 3), sentences consist of a logical side and an affective side that coexist in varying degree in a way that "no utterance in a language is entirely logical nor purely emotional". The prominence given to each side will depend on the speakers' intention when uttering their sentences. The second function of intonation, originally upheld by linguists such as Pike (1945) and Halliday (1967), refers to the link between intonation and grammar when it comes to the distribution of information within the utterance or the disambiguation of grammatically similar structures. Intonation can also be used as a focusing device (the accentual function) by the addresser "for contrastive or emphatic purposes" (Chun, 2002: 59). Thanks to this function, speakers can bring some parts of the utterance into or out of focus and indicate what information is new or what information has already been given in the dialogue. The discourse function, which owes its origins to Brazil (1975), is related to the achievement of coherence and cohesion beyond the sentence level. In this sense, intonation organises the discourse, regulates turn-taking and marks boundaries throughout sequences of tone units. The fifth function proposed by Wells (2006: 12) is the psychological function, necessary to arrange speech in different units "that are easy to perceive, memorize and perform" by speakers. Finally, the indexical function alludes to the crucial role of intonation to exhibit distinctive traits of personal and social identity amongst the interlocutors.

While the number and type of functions tend to vary slightly from author to author, a vast majority regard the expression of attitudinal meaning as the primary 
function of intonation in oral discourse (Crystal, 1969; O'Connor \& Arnold, 1973; Couper-Kuhlen, 1986; Monroy, 2005; Tench, 2011). This is but a reflection of the inextricable connection between attitudes and tones in speech. The sounds we use, as well as the words we use, are not chosen in an arbitrary way ( $\mathrm{O}^{\prime}$ Connor \& Arnold, 1973). We follow the patterns we learned as children and resort to them depending on our communicative purposes. Since the number of tones we can use in a language is limited, the kinds of attitudes we can assign to a particular pitch pattern will also be restricted. The possibility of building links between a specific pitch contour and a limited set of attitudes or intentions (Mompeán \& Monroy, 2010) allows us to ascribe a particular tone to a particular attitudinal content and a particular attitude to a particular tonal pattern. A wh-question, for instance, can be related to a businesslike attitude if uttered with a default falling tone, whereas it can sound encouraging and kind with the use of a rising tone. Similarly, a statement can convey a sense of detachment and reservation when uttered with a low fall but is bound to sound more casual and involved with the use of a high fall (O'Connor \& Arnold, 1973).

This correlation is paramount from the point of view of dubbing. Since the tonal patterns used by the original actors will determine to a great extent the attitude they adopt towards that particular situation, voice talents need to transmit the same attitudinal content in the dubbed version to make the new dialogue "not simply a 'correct' or 'precise' one but, equally important, a plausible one" (Mateo, 2014: 130). This is not to say that they are expected to imitate the tones of the on-screen characters, but rather that they are expected to convey the same attitudes by resorting to the repertoire of tones offered by their own language.

Although it goes without saying that intonation is not the only available means to express attitudes, and other prosodic and paralinguistic features as well as kinesics and lexical or grammatical choice can provide important clues about the actors' attitudinal intention, the focus of analysis in the present study is placed on intonation. One of the reasons for this is Monroy's (2005: 2) remark that, amongst all the possibilities for expressing attitude, "from a purely linguistic standpoint, intonation seems to be the basic means to convey attitudinal meaning". A further reason for the choice of intonation as the mainstay of this study is O'Connor \& Arnold's (1973: 5) idea that what allows actors to give different interpretations of a role previously played by another actor in a film or theatre play is essentially intonation, insofar as "it does provide important information which is not contained in any of the other features of utterances". The specificity of intonation and the possibility of establishing meaningful ties between tonal patterns and attitudes make this an eligible research topic in dubbing. 


\section{Dubbing attitudinal content}

According to Gottlieb (2005), dubbing is a type of isosemiotic translation of a polysemiotic text. This means that the source and the target texts make use of the same semiotic channel, in this case the verbal auditory channel (i.e., oral speech is rendered as oral speech). However, synchronization between the original and the dubbed versions is not strictly limited to the verbal auditory channel. The nonverbal auditory channel, in which intonation is embedded, and the nonverbal visual channel also need to be taken into consideration in order to achieve a harmonious result. Even though the study of the nonverbal component of speech has taken a back seat in AVT research, especially as compared to the attention devoted to the verbal component, nonverbal features such as intonation occupy a fundamental place in dubbing. Intonation needs to be regarded as an intrinsic part of the audiovisual construct, one that contributes to understanding how characters behave and communicate with each other and that can even modify the semantic content of the utterance (Sánchez-Mompeán, 2016).

One of the tasks of voice talents is precisely to interpret the character's words within the context they have been uttered in. In Mateo's (2014) view, one of the cornerstones for an effective communication is primarily based on the interpretation of the speaker's meaning, which is very often transmitted by intonational features. In order that the original message is interpreted correctly, Cuevas Alonso (2017) emphasizes the need to understand how intonation works and what meaning this suprasegmental feature adds to the whole utterance. He argues that intonation can help dubbing actors opt for a particular interpretation while ruling out other interpretations of the same message. Intonation thus acts as a valuable tool for guiding dubbing practitioners through their task and should be mastered to comprehend and exploit its expressive richness. Voice talents are expected to grasp the attitude intended by the character and, under the supervision of the dubbing director (Whitman-Linsen, 1992; Agost, 1999), reproduce the same attitudinal content in the dubbed version.

The following example (from Crystal, 1975: 3) illustrates how intonation can modulate the attitudinal meaning of the sentence and influence its oral delivery into Spanish. In this case, by modifying the pitch direction (from fall to rise) in a whquestion such as "What are you doing?" the speaker's attitude changes. In order to reflect the intended attitudinal content in Spanish the dubbing actor will have to interpret correctly the attitudinal meanings added by intonation and convey the same attitude in the target language. From a translational viewpoint, the written form of the question would remain the same in both examples, the difference lying in the oral version delivered by the voice talent. 
1) a. What are you $\searrow$ doing? (serious and abrupt)

b. What are you $\lambda$ doing? (friendly and interested)

Despite the fact that contextual factors as well as facial expression and body language can often help dubbing actors to infer the attitude adopted by the original character, intonation is sometimes the only available tool that leads to the correct answer. In general terms, the unsuccessful rendering of the attitude intended by the speaker might bring about an unnatural rendition, a shift in characterisation or in the comic purpose of the text (Hidalgo Navarro, 2011) and, ultimately, an unfavourable reaction from the target audience. Therefore, the attitudinal function of this suprasegmental feature as well as its essential role in spoken discourse cannot be underestimated or taken for granted in dubbing from both an academic and a professional perspective.

\section{Methods}

The study proposed here intends to offer a better insight into the dubbing of attitudes through intonation. The aim is to analyse the (un)successful rendering of attitudes in a Spanish dubbed corpus by comparing the tonal patterns used in both the original and dubbed versions. The following research questions will be addressed:

1. Is the attitudinal content attached to the on-screen actors' intonation reflected successfully in the dubbed version?

2. Are any regular patterns or prevailing trends observed in the conveyance of attitudes in the dubbed text?

3. In what ways can unsuccessful renderings affect the target audience's comprehension?

For the purpose of this study, attention will only be directed to those oral extracts where attitudes are predominantly transmitted and reflected through tonal variation. For instance, attitudinal content exclusively conveyed by body language or by other paralinguistic features will be discarded.

Before moving on to the procedure and the corpus used in the analysis, it is worth noting that the aim of this paper is not to judge the dubbing actors' job but to evaluate whether the attitudinal content transmitted intonationally in the source text is rendered in the target version (un)successfully. Although it is the oral discourse as dubbed by the voice talents of the sitcom the one to be assessed here, the dubbing actor is obviously regarded as one more agent of the dubbing process, one who 
collaborates with other professionals to make an audiovisual product available in a different language to a different public (Chaume, 2012; Cuevas Alonso, 2017).

\subsection{Design}

To measure the (un)successful rendering of attitudes through tonal patterns in the dubbed text, an inventory of nine tones, namely low fall, high fall, low rise, high rise, low level, mid level, high level, fall-rise and rise-fall, was selected. This repertoire of tones suffices to account for the usage and variability of patterns in both languages (O'Connor \& Arnold, 1973; Monroy, 2002). The occurrence of these nine tones was examined in four utterance types: statements, questions, exclamations and commands. Drawing on O'Connor \& Arnold (1973), Brown et al. (1980) and Cruttenden (1997), who state that some attitudes are more likely to occur with some types of tonal patterns, it was possible to establish a direct correlation between the tone used in a particular utterance type and the attitudinal content related to that tone. This study adheres to the works by numerous experts in the field of intonation in both English (Crystal, 1969; O’Connor \& Arnold, 1973; Collins \& Mees, 2003; Wells, 2006; Tench, 2011) and Spanish (García-Lecumberri, 1995; 2003; Gutiérrez Díez, 1995; 2005; Monroy, 2002; 2005) to determine which attitudes can be related to a specific tonal pattern. This research is thus underpinned by existing studies that help envisage a taxonomy able to associate a tonal pattern with a repertoire of attitudinal meanings.

\subsection{Procedure}

The procedure followed in the corpus analysis can be summarised in several consecutive steps. The first stage consisted of the manual transcription of the original and dubbed scripts and the division of the dialogue into intonation phrases (i.e., a portion of spoken material with its own intonational pattern). The second step was to cut the original and dubbed intonation phrases into individual utterances with an online audio cutter and to arrange the samples per utterance type. Then source text and target text fragments were introduced into the speech analysis software SFS/WASP (Waveforms Annotations Spectrograms and Pitch), a very useful program developed by Mark Huckvale from the University College London to obtain the exact pitch contour of a recorded utterance. For illustrative purposes, a SFS/WASP screenshot is provided in Figure 1 below. 
Figure 1. SFS/WASP screenshot

$$
\begin{aligned}
& \text { Use mouse buttons to position } \\
& \text { left and right cursors. } \\
& \text { Use arrows to zoom in/out } \\
& \text { and scroll left/right. } \\
& \text { Press [A]label[RFTIIRN] to } \\
& \text { add annotation at left cursor. } \\
& \text { Press [B]label[RETURN] to } \\
& \text { add annolation aL right cursor. }
\end{aligned}
$$

The next step of the process included an auditory and visual inspection of contours conducted by the researcher of this study in order to identify the prenuclear and nuclear patterns of each intonation phrase. Taking the aforementioned studies as a starting point, the tonal patterns observed per utterance type in both English and Spanish were associated with one or several attitudinal meanings. Then, the tonal patterns used by the original actors were compared to their dubbed counterparts as far as their attitudinal content was concerned. When the tonal patterns used in Spanish managed to convey the same attitude as the English utterance, the dubbed sentence was judged as a successful rendering. When the tonal patterns adopted by the voice talent failed to reflect the same attitude as the original sentence, the dubbed utterance was deemed as an unsuccessful rendering. The results obtained from the comparative analysis were then quantified and divided into two different groups: one including all those instances that successfully reflected the original attitudinal content and one gathering those cases that failed to transmit the attitude conveyed intonationally by the original character. Finally, data were explored from a qualitative point of view in order to identify regularities or prevailing trends in the conveyance of attitudes in the dubbed text and to draw conclusions on how unsuccessful renderings might affect the target viewers' comprehension.

\subsection{Corpus}

The popular sitcom How I met your mother (ST) and its dubbed version into Castilian Spanish (TT) was selected as the corpus of this study. The bilingual parallel corpus under examination comprised a total of 720 utterances extracted from 12 episodes (6 in English and 6 in Spanish) that featured around 270 minutes of fictional dialogue. Only speech produced by the five main characters of the sitcom, namely Ted Mosby, Barney Stinson, Marshall Eriksen, Robin Scherbatsky and Lily Aldrin, was singled out and analysed in this study to ensure consistency. Although, as shown by Sánchez-Mompeán (2016), intonation can also exert a substantial impact on the way 
oral discourse is translated into Spanish, the focus of attention in this paper is on the oral rendition of the discourse as delivered by the dubbing actors of the sitcom. As for the genre selected for the present research, the situation comedy was mainly chosen for its proneness to mirror colloquial and spontaneous conversation (RomeroFresco, 2009; Baños, 2014), its expressive possibilities (Savorelli, 2010) and its comic purpose. As argued by Zabalbeascoa (2001), intonation is indeed a strategic device to reflect colloquialism, to provide the oral text with more expressiveness and to trigger humorous situations.

\section{Results and discussion}

The total number of intonation phrases analysed was 720 in both languages. After examining the tonal patterns of the utterances under study in the parallel corpus, the comparative analysis revealed a high percentage of dubbed utterances that failed to reflect the attitudinal content transmitted intonationally by the original actor. As shown in Figure 2 below, 214 out of 360 dubbed utterances (59.4\%) did not convey the attitude intended by the original speaker, whereas this attitudinal content was successfully delivered in 146 dubbed utterances (40.6\%). The findings show that the dubbing actor very often resorts to a tonal pattern that fails to reproduce the attitude intended in the original utterance, maybe because the wrong attitude is inferred from the character's intonation.

Figure 2. Results obtained from the comparative analysis

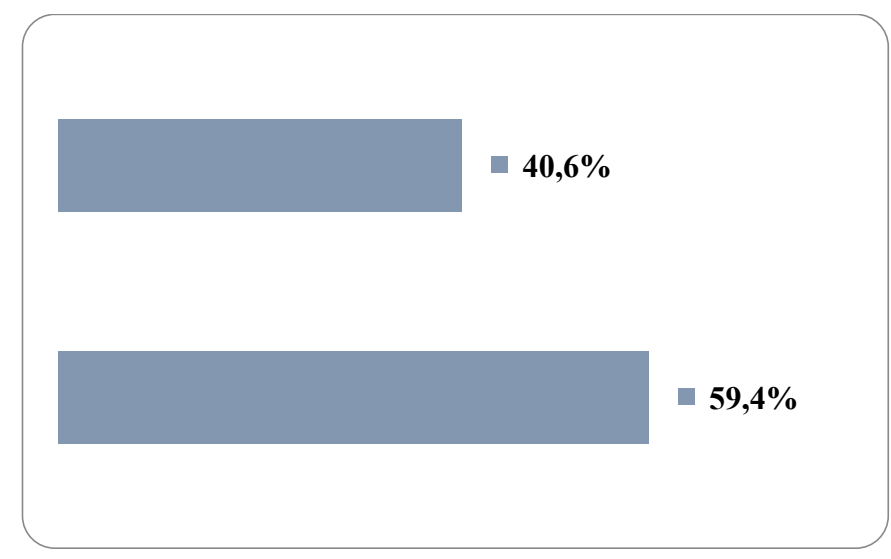

A notable difference has also been found regarding the (un)successful rendering of attitudes per utterance type. The analysis has shown that the attitudinal content conveyed in the form of exclamatory sentences tends to be delivered successfully in the 
dubbed version. A possible explanation for this finding could be the expressive load characterising these types of utterances, which might make it easier for voice talents to grasp and reproduce the attitude transmitted intonationally by the on-screen actor.

Due to space constraints, the focus will be placed here on those dubbed utterances that failed to reflect the original attitudinal content (59.4\% of the corpus analysed). After analysing and comparing the bilingual corpus under study, four main patterns were detected in the conveyance of attitudes in the dubbed dialogue: (a) the reduction of the emotional involvement, interest and surprising load, (b) the mitigation of sarcasm and an air of detachment, (c) the use of a more categorical attitude when conveying a questioning tone or a reserving judgment, and (d) the rendition of confirmatory-seeking questions as information-seeking questions. These four trends will be exemplified for the sake of clarification. (The audio-visual extracts under analysis in the present paper are available upon request.)

The three examples given below illustrate the first trend found in the analysis. The high falling tone has been replaced either by a level or a low pitch-range, thus reducing the emotional involvement as well as the interest and surprising load in the dubbed version.

In the first example, Ted resorts to a high fall with a twofold purpose: on the one hand, to offer his opinion about the fact that Marshall has accepted to work for a profit-seeking company and, on the other hand, to show interest in his friend's success. Broadly speaking, the fall is the commonest tone for declarative sentences and tends to imply definiteness and completeness. Yet, the use of this tone along with the use of a particular pitch-range and a particular head can add several attitudinal meanings to the sentence (Monroy, 2005). The high fall on the nucleus and the stepping downward head (Monroy, 2002) introduce a note of mild surprise on the part of the speaker and an underlying thought (Tench, 2011), in this case: "I am happy for you, but I think it is ironic that you now take the type of job you always complained about". This tonal pattern thus makes Ted sound mildly surprised, involved and even a bit sarcastic (Tench, 2011). The attitude implied intonationally by Ted triggers the answer given by Marshall, who immediately justifies himself for having accepted that job by admitting that "it's just an internship to make a little money".

The attitude implied by Ted's intonation should be easily inferred from the English audience but might not be so obvious in the Spanish version due to the tone adopted by the dubbing actor. A sustained high head and a low falling contour mitigates the involvement and the surprised attitude attached to the character's intonation and leaves out the sarcastic load. Instead, the Spanish utterance sounds more detached and unemotional, as if Ted's intention was just to express his opinion or belief (Quilis, 
1993). The comparison between the tonal pattern used in the original (a) and in the dubbed (b) sentences is shown in the following SFS/WASP screenshots.

Example 1 (season 1 - episode 17)

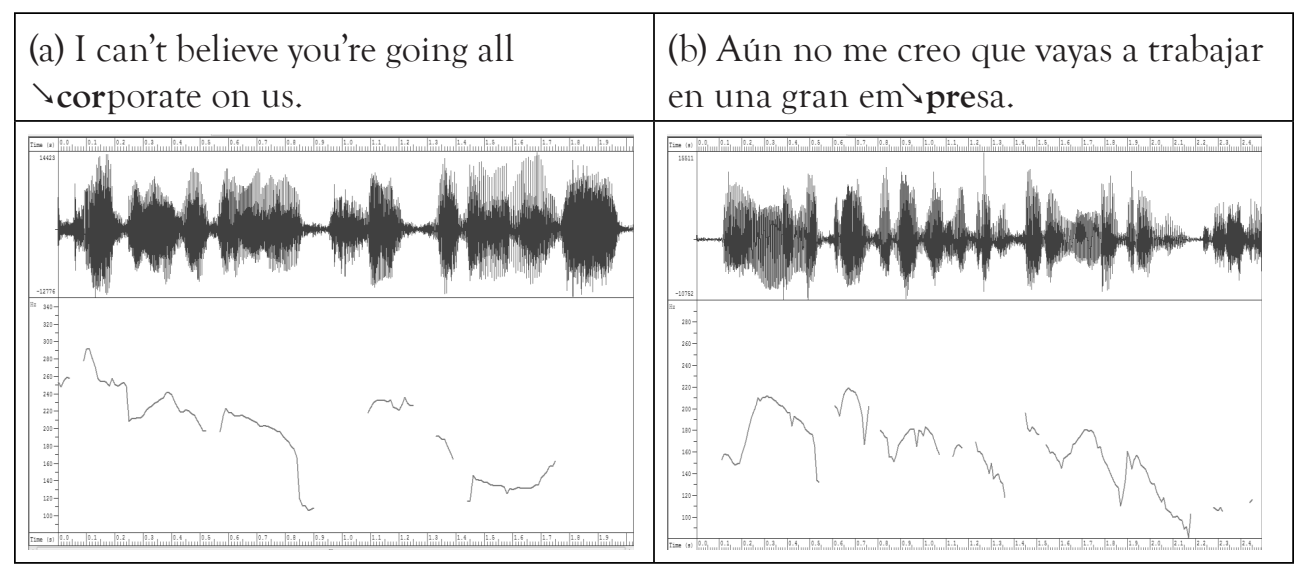

*Syllable in bold representing the nucleus. ${ }^{* *}$ Arrows representing pitch direction ( $>$ high fall and \ low fall)

In the second example, the emotional involvement and excitement of Marshall at having almost reached 200,000 miles driving his old car is inferred from the use of a high head and a high fall (O'Connor \& Arnold, 1973) and reinforced by an increase in the character's loudness. Both intonation and loudness play a paramount role to reflect the attitude of the character towards that particular situation. However, the Spanish utterance seems to hint at a different attitudinal meaning. In the dubbed version, the nuclear tone falls by default on the last word of the sentence, given that, as noted by Gutiérrez Díez (2005: 132), the rule in Spanish is to accent the last lexical item "regardless of the nature of such word". This shift in the focus placement along with the use of a (mid) level contour in dubbing make Marshall still sound anxious but much more relaxed and less emotionally involved than in the English version.

Moreover, the addition of laughter at the end of the dubbed sentence, absent in the source text, contributes to mitigating the original strength of feeling (Tench, 2011), which leads to the anxiety brought about in the subsequent shots because the engine stops working and the car fails to hit 200,000 miles. As far as loudness is concerned, whereas the English text (a) increases in intensity up to $85 \mathrm{~dB}$ (decibels), it ranges between 67-70 dB in Spanish (b) and hardly rises when uttering the nucleus. 
Example 2 (season 2 - episode 17)

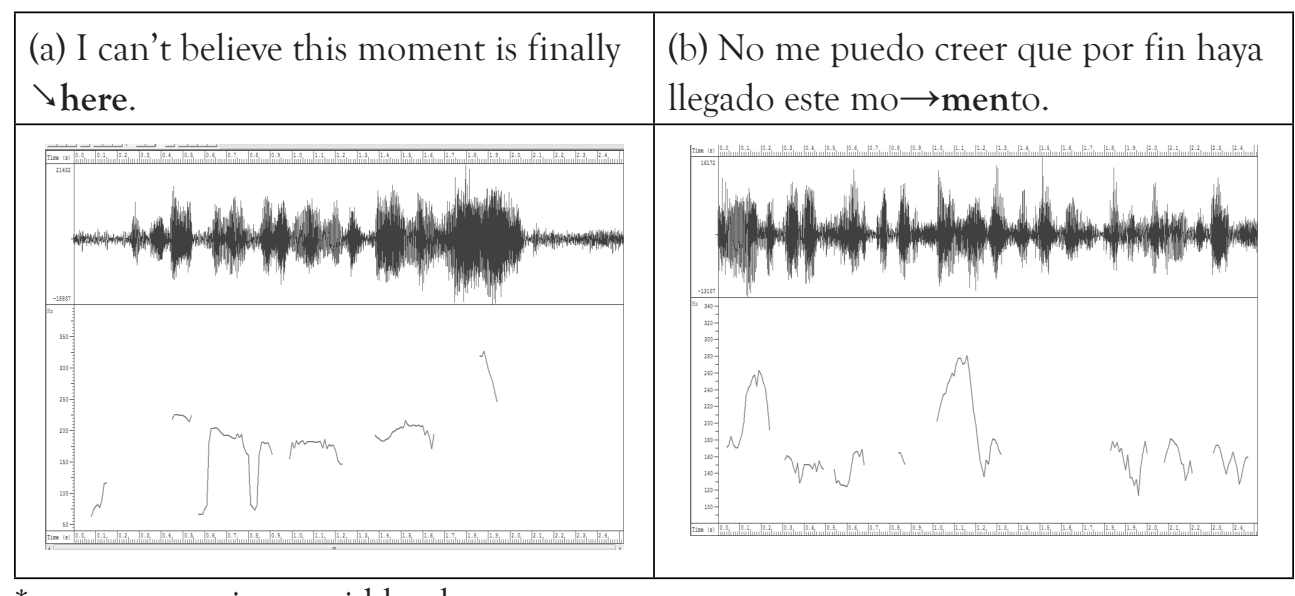

${ }^{*} \rightarrow$ representing a mid level tone.

A change in the attitude intended by the original character is also notable in Example 3. In this case, Lily's intonation is characterised by a sustained high head and a high fall, a tonal pattern that tends to reflect a deep interest on the part of the speaker and introduces a note of concern and agitation (O'Connor \& Arnold, 1973). Lily's attitude is also reinforced here with the elongation of the first syllable of the nucleus (da:y). If we analyse this utterance by taking into consideration the visual code as well as the situational context, there is no doubt that Lily's intonation in the original version is determined by Marshall's sad face when he arrives home from his new job. The visuals thus lead Lily (and the audience) to expect a negative comment to her question before listening to Marshall's answer.

In this particular example, the dubbed version could have made use of the same contour as the English question, insofar as this pattern is also the best choice to express the emotional involvement of the speaker in Spanish (Navarro Tomás, 1944). However, the level tone coupled with a low key reduce Lily's involvement and interest in the target dialogue (Mompeán \& Monroy, 2010). The attitude of concern and agitation transmitted by the original character in English has been replaced by a more enthusiastic question in Spanish that seems to ignore Marshall's sad face. 
Example 3 (season 1 - episode 17)

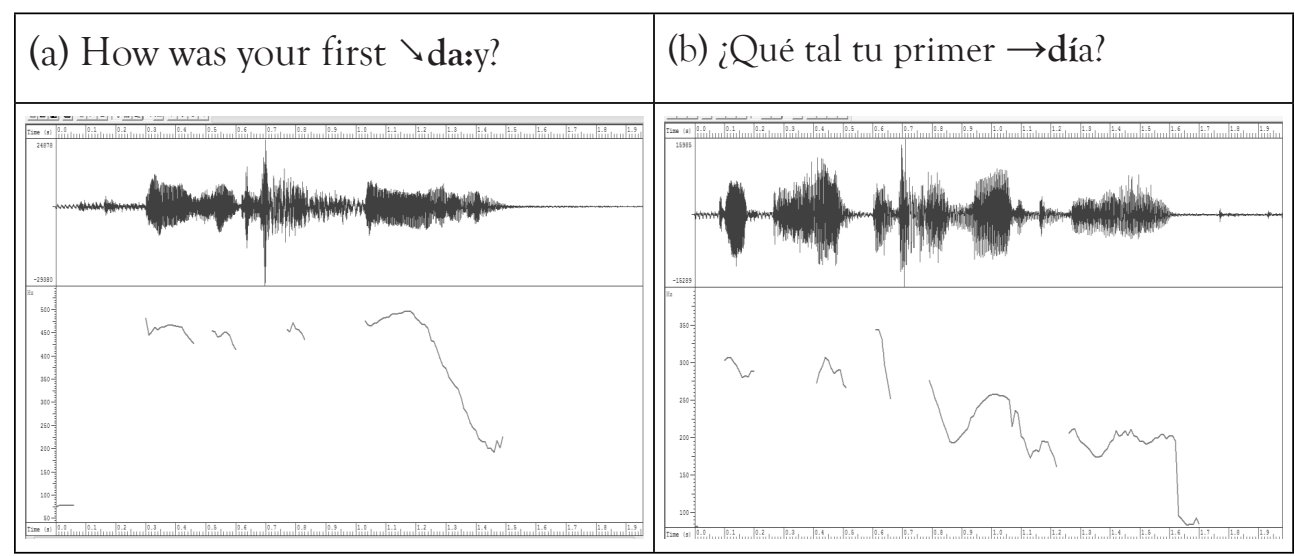

* : representing the elongation of the vowel sound.

The second trend detected in the corpus is related to the mitigation of sarcasm and an air of detachment, as illustrated in the following two examples. This trend seems to be highly associated with the replacement of the rise-fall adopted in the original utterance by a low fall in the dubbed version. In fact, the use of the rise-fall in English merits attention due to its implicative load in speech. As described by Collins \& Mees (2003: 129), this tone, which is more frequently employed in English than in Spanish (Monroy, 2005), tends to introduce "an implication of an additional but unspoken message". This implication can be introduced in the form of irony or veiled sarcasm (Cruttenden, 2008), as is the case in Example 4.

In this scene, Ted and Marshall take Marshall's car to a local garage to get it fixed. Since Lily wants them to help with the paper folding she is preparing for her wedding with Marshall, she convinces Robin and Barney to go and meet their friends there while they wait for the car to be repaired. Even though Barney goes to the garage against his will, when they arrive he tells Ted and Marshall that the three of them insisted on joining them. The rise-fall adopted to utter the nucleus makes the audience aware that he is clearly being sarcastic and that he was compelled by the girls, thus creating a hilarious situation.

In the Spanish version of the utterance, the falling head and the low falling tone adopted by the dubbing actor successfully transmit the lack of excitement and of enthusiasm contained in the character's words. However, this tone also reduces the sarcastic implication in the dubbed text. As a result, the attitude intended by Barney in the original dialogue sounds less humorous in the dubbed version and the perception gained by the target audience is likely to vary. 
Example 4 (season 2 - episode 17)

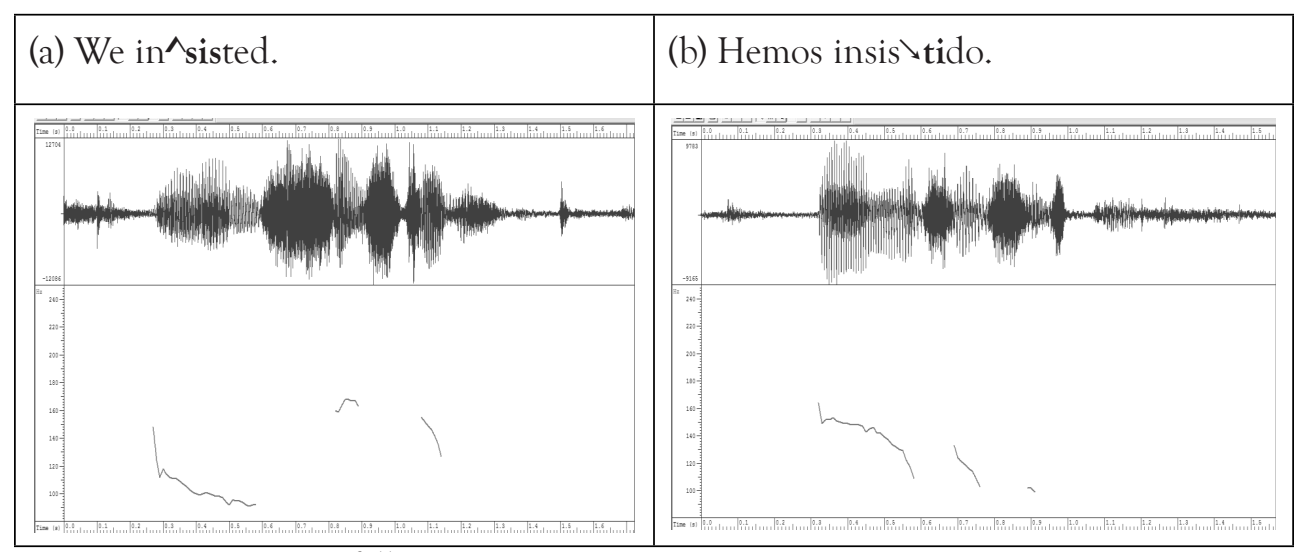

${ }_{*} \wedge$ representing a rise-fall.

Another case of rise-falling tone is featured in Example 5. The rise-fall preceded by a sustained high head can express feelings of surprise and awe (Halliday, 1970) and even a hint of accusation (O'Connor \& Arnold, 1973). Therefore, the use of this tone in the English utterance carries several implications from an attitudinal standpoint. In this scene, Ted tells Robin that he is in love with her and that he is moving to Chicago to put some distance between them. In Robin's use of intonation it is possible to infer that she is highly impressed by Ted's words (Crystal, 1975; Cruttenden, 2008) and even sounds somewhat accusatory (O'Connor \& Arnold, 1973). The audience is bound to perceive from her use of intonation that she is not trying to persuade Ted to stay in New York but disagrees with his decision to leave.

The use of a low fall in Spanish makes the character sound more detached and unsympathetic (Monroy, 2005), as if she was just presenting a fact rather than expressing her inner feelings. This pattern could thus make it difficult for the target audience to interpret the attitude intended by the original actor successfully. 
Example 5 (season 9 - episode 17)

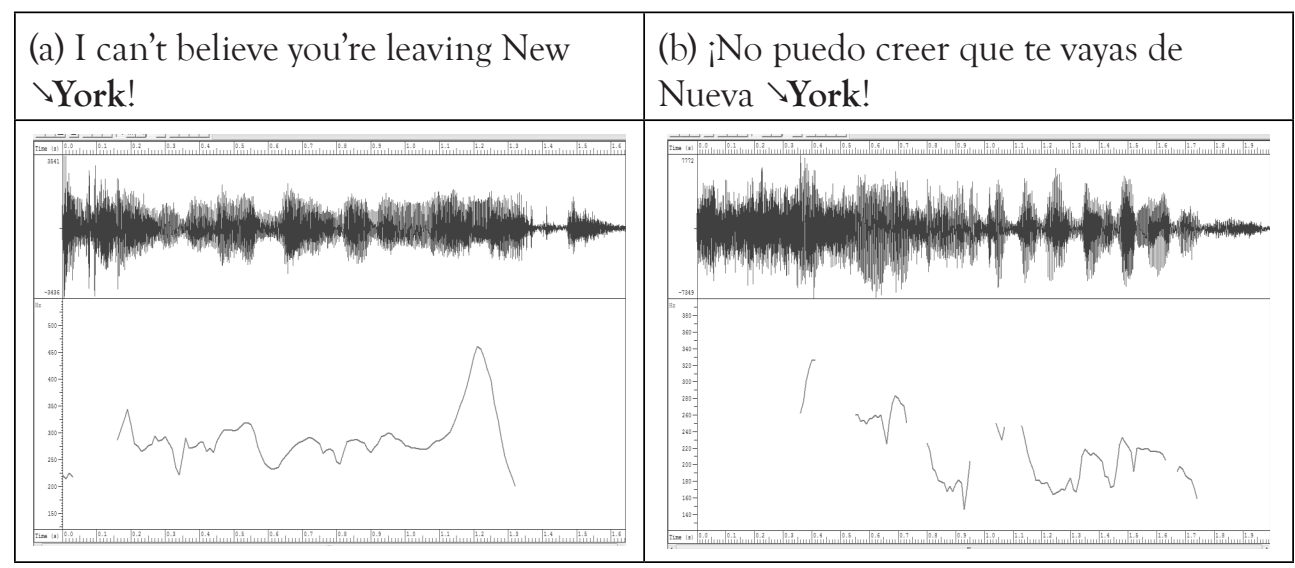

The use of a more categorical attitude when conveying a questioning tone or a reserving judgment has also been detected in the corpus under study. In Example 6 below, the low rise at the end of the English utterance preceded by a sustained low head implies a condescending attitude and introduces a reserving judgement (O'Connor \& Arnold, 1973). This pattern can also be used to sound warm and gentle and to downgrade the impact of the meaning underlying the speaker's comment (Collins $\&$ Mees, 2003). The attitudinal content transmitted by this tonal pattern is perfectly suitable within the situational context of the statement. In this scene, Marshall is forced by his two elder brothers to drive to the coffee shop completely naked. When he arrives there, the drive-through attendant asks Marshall if he realised that he is not wearing any clothes. Although Marshall feels terribly embarrassed, he reserves his real feelings and tries to sound calm and gentle to defuse that tense situation. If the English utterance is compared to its Spanish counterpart, we find that the descending head and the low falling tone adopted by the dubbing actor sound more categorical and less reserved in Spanish than in English, thus creating a different impression about Marshall's attitude in this scene. 
Example 6 (season 2 - episode 17)

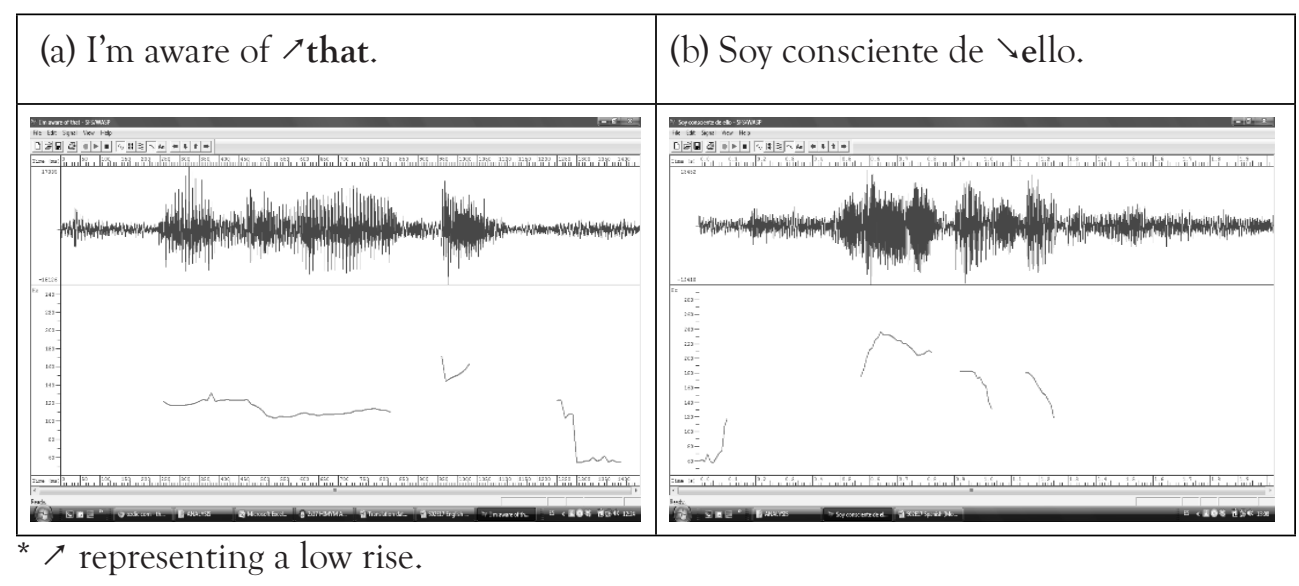

One of the most remarkable instances representing a shift in the questioning tone of the original utterance is shown in Example 7. In this scene, Ted tells Marshall that Robin kissed him before she took her plane to Russia. According to Wells (2006), yesno questions generally take a rise and indicate that the speaker is asking for information and expects a more elaborated reply from the hearer (Monroy, 2012) at the same time as showing interest in the listener's answer. In Spanish, however, the questioning tone has been replaced by a more confident and somewhat insistent attitude with the use of a falling tone (Crystal, 1975). This pattern gives the impression that Ted is completely sure about Marshall's viewpoint and that there is no need to ask about his opinion. As a result, Marshall's answer to Ted's question in the original dialogue ("No, I'm not shocked") is to be perceived by the target audience as a contradiction to Ted's assertion in the dubbed version.

It is difficult to determine whether this change in intonation and, by extension, in the illocutionary force of the utterance under analysis took place in the presynchronisation (by the translator or the dialogue writer) or in the post-synchronisation (by the dubbing director or the dubbing actor) stage of the dubbing process. Whatever the case may be, there is no doubt that how characters say what they say exerts a direct impact on attitudinal meaning and should be interpreted and delivered correctly to avoid a potential change in the attitude intended by the original speaker. 
Example 7 (season 7 - episode 17)

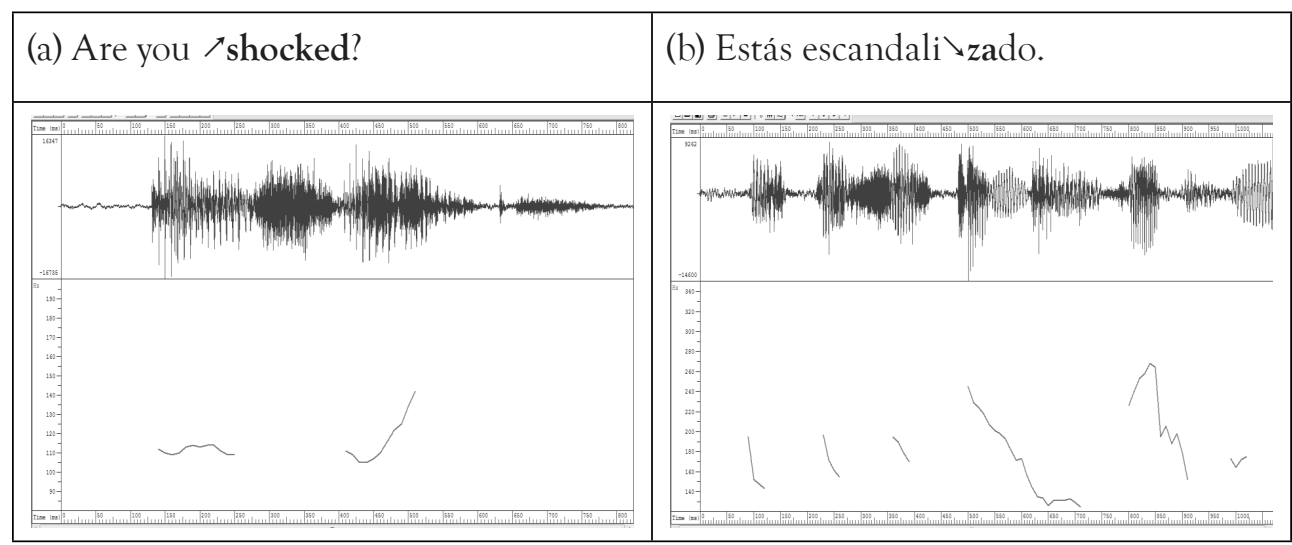

Finally, the rendition of confirmatory-seeking questions as information-seeking questions has been observed in the corpus. In Example 8, given the absence of the subject-verb inversion, intonation holds the key to determining whether the character wants to ask a question or state a fact. In this scene, the speaker, Barney, puts in a request for confirmation by drawing upon a level tone. The level tone accounts here for the questioning nature of the English utterance and the confirmatory-seeking intention of Barney's words. Yet, the high rise in Spanish tinges the interrogative sentence with a note of surprise (García-Lecumberri, 2003) and turns the original confirmatory yes-no question into an information-seeking question (Estebas-Vilaplana $\&$ Prieto, 2009). The result is a change in the attitude intended by the original speaker.

Example 8 (season 3 - episode 17)

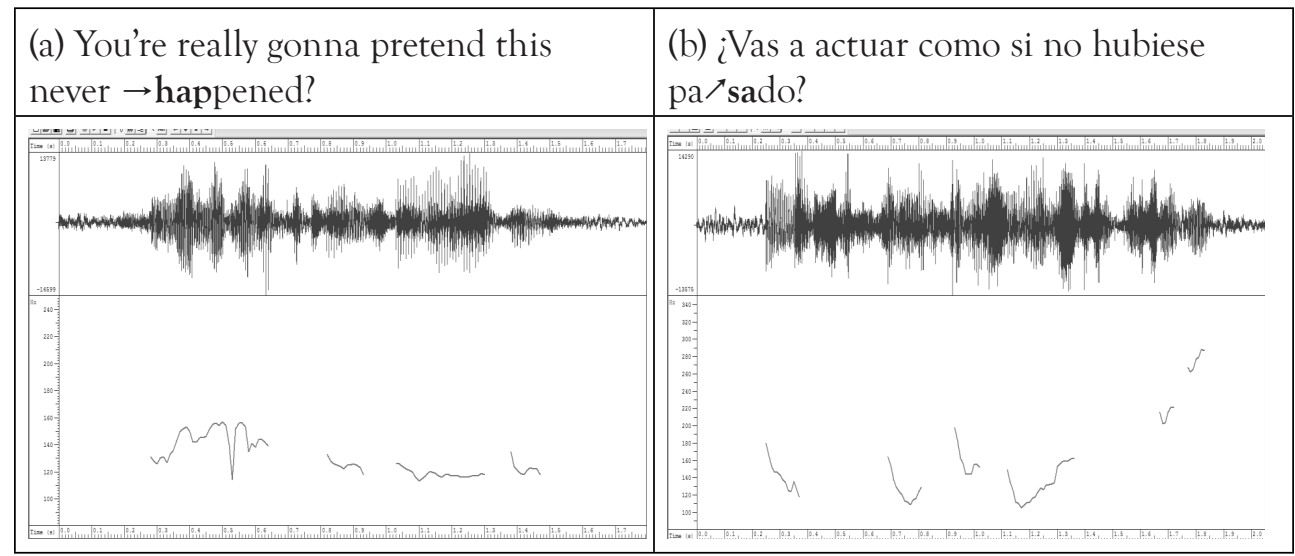




\section{Conclusions}

Intonation has not been a recurrent research topic amongst dubbing scholars nor has it received the attention it merits as far as training and teaching are concerned. The great relevance that this suprasegmental trait bears in oral discourse and its leading role in the conveyance of attitudinal meaning pave the way for a thorough analysis of how intonation is interpreted and produced in dubbed speech. The focus has been placed here on the (un)successful rendering of attitudes through tonal patterns in Spanish dubbing. The strong correlation that exists between the tone used and the attitudinal content intended by the speaker has invited comparison between the source and target dialogues to explore whether the English actors and the Spanish dubbing actors have adopted the same attitudes by resorting to the tonal repertoire offered in their respective languages.

The results of the comparative analysis show that the attitudinal content intended in the original version was successfully rendered in $40.6 \%$ of the cases, whereas $59.4 \%$ dubbed utterances failed to reflect the attitude transmitted intonationally by the on-screen characters. The trends observed in the conveyance of attitudes in the dubbed text are as follows: (a) the reduction of the emotional involvement, interest and surprising load, (b) the mitigation of sarcasm and an air of detachment, (c) the use of a more categorical attitude when conveying a questioning tone or a reserving judgment, and (d) the rendition of confirmatory-seeking questions as informationseeking questions. Most unsuccessful renderings are thus related to the use of a tonal pattern that does not reflect the attitude intended in the original utterance and brings about a different interpretation in the target language. As a result, the perception gained by the audience in Spanish and their comprehension can be affected, even more if there is an apparent contradiction between what the characters are saying and what their attitude towards that situation is - or between how characters say what they say and what is shown on screen- or if the intended comic purpose is reduced or completely lost in the dubbed version.

We agree with Mateo (2014) that the capital importance of intonation for both the interpretation and the conveyance of attitudinal meaning stresses the need to incorporate its study into the field of dubbing from both a theoretical and a practical point of view. In fact, the lack of research in this area along with the lack of specific training for dubbing professionals to learn about the singularity of intonation and its relevance in oral speech could have a detrimental effect on the final version delivered in Spanish. Baños (2014: 409) wrote that in the case of translation "the translator takes the role of the scriptwriter, and should thus master the linguistic features available in the target language". If we extrapolate this sentence to the context of dubbing, the voice talent would take the role of the original actor in the Spanish version and should 
thus master the tonal patterns available in the target language. It is worth noting, however, that the paramount role played by intonation in dubbing should not be overlooked by any of the practitioners taking part in the process.

Amongst the future avenues of research to expand this topic, reception studies, which have witnessed an upsurge in popularity in recent years, will prove especially useful to achieve more quality in the final outcome and to cast new light on the audience's perception and comprehension when watching an audiovisual product dubbed into Spanish. With a view to teaching future professionals, there is little doubt that intonation should occupy a more prominent place in dubbing courses, and specific training should be given in this area.

\section{References}

Agost, R. (1999) Traducción y doblaje. Palabras, voces e imágenes. Barcelona: Ariel.

Baños, R. (2014) Orality markers in Spanish native and dubbed sitcoms: Pretended spontaneity and prefabricated orality. Meta 59(2): 406-435.

Brazil, D. (1975) Discourse Intonation: Discourse Analysis Monographs no. 1. Birmingham: English Language Research, University of Birmingham.

Brown, G., Currie, K.L. \& J. Kenworthy. (1980) Questions of intonation. Baltimore: University Park Press.

Cantero, F.J. (2002) Teoría y análisis de la entonación. Barcelona: Edicions de la Universitat de Barcelona.

Chaume, F. (2012) Audiovisual Translation: Dubbing. Manchester: St. Jerome Publishing.

Chun, D. (2002) Discourse Intonation in L2: From Theory and Research to Practice. Amsterdam/Philadelphia: John Benjamins.

Collins, B., and I.M. Mees. (2003) Practical Phonetics and Phonology. New York: Routledge.

Couper-Kuhlen, E. (1986) An introduction to English prosody. London: Edward Arnold.

Cruttenden, A. (1997) Intonation (2 ${ }^{\text {nd }}$ ed). Cambridge: Cambridge University Press.

----. (2008) Gimson's Pronunciation of English ( $\left.7^{\text {th }} \mathrm{ed}\right)$. London: Hodder Education.

Crystal, D. (1969) Prosodic systems and intonation in English. Cambridge: Cambridge University Press. 
----. (1975) The English Tone of Voice. London: Edward Arnold.

----. (1985). A dictionary of linguistics and phonetics ( $2^{\text {nd }}$ ed). Oxford: Blackwell Publishing.

Cuevas Alonso, M. (2017). Multimodalidad, comunicación y doblaje. La entonación. In X. Montero Domínguez (ed) 2017 El Doblaje. Nuevas vías de investigación. Granada: Editorial Comares.

Estebas-Vilaplana, E. \& P. Prieto. (2009) La notación prosódica en español. Una revisión del Sp_ToBI. Estudios de Fonética Experimental 18: 263-283.

García-Lecumberri, M.L. (1995) Intonational Signalling of Information Structure in English and Spanish. Bilbao: UPV/EHV.

----. (2003) Análisis por configuraciones: La escuela británica. In P. Prieto (coord) Teorias de la entonación. Barcelona: Ariel.

Gottlieb, H. (2005) Multidimensional Translation: Semantics turned Semiotics. Proceedings of the Marie Curie Euroconferences MuTra: Challenges of Multidimensional Translation. Saarbrücken, Germany, 2005. http://www.euroconferences.info/ proceedings/2005_Proceedings/2005_Gottlieb_Henrik.pdf. 7 March 2018.

Gutiérrez Díez, F. (1995) La función demarcativa de la entonación en inglés, castellano y catalán. Murcia: Servicio de Publicaciones Universidad de Murcia.

----. (2005) Intonation focus in the interlanguage of a group of Spanish learners of English. Revista Alicantina de Estudios Ingleses 18: 129-147. Mouton.

Halliday, M.A.K. (1967) Intonation and grammar in British English. The Hague:

----. (1970) A Course in Spoken English: Intonation. Oxford: Oxford University Press.

Hidalgo Navarro, A. (2011) Humor, prosodia e intensificación pragmática en la conversación coloquial española. Verba 38: 271-292.

Hirst, D. \& A. Di Cristo. (1998) A survey of intonation systems. In D. Hirst and A. Di Cristo (eds) Intonation systems: A survey of twenty languages. Cambridge: Cambridge University Press.

Mateo, M. (2014) Exploring pragmatics and phonetics for successful translation. VIAL 11: 111-136.

Mompeán González, J.A. \& R. Monroy Casas. (2010) Nuclear tones in English: The case of household consumer products TV commercials. ReVEL 8(15): 229-241. http://www.revel.inf.br/files/artigos/revel_15_nuclear_tones_in_english.pdf. 22 March 2018. 
Monroy Casas, R. (2002) El sistema entonativo del murciano coloquial. Aspectos comunicativos y actitudinales. Estudios Filológicos 37: 77-101.

----. (2005) Spanish and English intonation patterns. A perceptual approach to attitudinal meaning. Pragmatics 83 Beyond New Series 140: 307-324.

----. (2012) La pronunciación simplificada del inglés británico. Murcia: Servicio de publicaciones de la Universidad de Murcia.

Navarro Tomás, T. (1944) Manual de entonación española. New York: Hispanic Institute in the United States.

Nilsenová, M. \& M. Swerts. (2012) Prosodic adaptation in language learning. In J. Romero-Trillo (ed) Pragmatics and prosody in English language teaching. Dordrecht/ Heidelberg/New York/London: Springer.

O'Connor, J.D. \& G.F. Arnold. (1973) Intonation of Colloquial English (2 $\left.{ }^{\text {nd }} \mathrm{ed}\right)$. London: Longman.

Pike, K.L. (1945) The intonation of American English. Ann Arbor: University of Michigan Press.

Quilis, A. (1993) Tratado de fonología y fonética españolas. Madrid: Gredos.

Romero-Fresco, P. (2009) Naturalness in the Spanish dubbing language: A case of not-so-close Friends. Meta 54(1): 49-72.

Sánchez-Mompeán, S. (2016) 'It's not what they said; it's how they said it': A corpus-based study on the translation of intonation for dubbing. In A.M. Rojo López and N. Campos Plaza (eds) Interdisciplinarity in Translation Studies. Theoretical Models, Creative Approaches and Applied Methods. Bern: Peter Lang.

Savorelli, A. (2010) Beyond Sitcom. New Directions in American Television Comedy. North Carolina: McFarland \& Company Inc.

Tench, P. (2011) Transcribing the sounds of English: A phonetics workbook for words and discourse. Cambridge: Cambridge University Press.

Wells, J. (2006) English intonation: An introduction. Cambridge: Cambridge University Press.

Whitman-Linsen, C. (1992) Through the dubbing glass. The synchronization of American Motion Pictures into German, French and Spanish. Frankfurt am Main: Peter Lang.

Zabalbeascoa, P. (2001) La traducción del humor en textos audiovisuales. In M. Duro (coord) La traducción para el doblaje y la subtitulación. Madrid: Ediciones Cátedra. 